\title{
The association between vascular endothelial growth factor-C, its corresponding receptor, VEGFR-3, and prognosis in primary breast cancer: A study with 193 cases
}

\author{
HIROKO BANDO ${ }^{1,4}$, HERBERT A. WEICH ${ }^{5}$, SHINICHIRO HORIGUCHI ${ }^{2}$, \\ NOBUAKI FUNATA ${ }^{2}$, TAEKO OGAWA ${ }^{1}$ and MASAKAZU TOI ${ }^{1,3}$
}

\begin{abstract}
Departments of ${ }^{1}$ Surgery, ${ }^{2}$ Pathology and ${ }^{3}$ Clinical Trials and Research, Tokyo Metropolitan Komagome Hospital, Tokyo Metropolitan Cancer and Infectious Disease Center, 3-18-22 Honkomagome Bunkyo-ku, Tokyo 113-8677; ${ }^{4}$ Department of Surgery, Institute of Clinical Medicine, University of Tsukuba, 1-1-1 Tennodai, Tsukuba-shi, Ibaraki, Japan; ${ }^{5}$ Department of Gene Regulation and Differentiation; National Research Centre for Biotechnology, Braunschweig, Germany
\end{abstract}

Received September 6, 2005; Accepted October 28, 2005

\begin{abstract}
Lymphangiogenesis plays an important role in several normal and pathological conditions, such as wound healing, pathogen infection, inflammation or the metastasis formation of endothelial malignancies. Vascular endothelial growth factor-C (VEGF-C) and VEGF-D are important and specific regulatory factors for lymphatic endothelial proliferation and lymphangiogenesis. Both growth factors mediate their biological activity mainly by VEGF receptor-3 (VEGFR-3, Flt-4). In this study, we measured intratumoral levels of VEGF-C and VEGFR-3 through enzyme-linked immunosorbent assay (ELISA) in 193 primary breast cancer tissues and examined their prognostic values. A significant correlation was found between the VEGF-C and VEGFR-3 protein levels. High VEGF-C levels were associated with low-grade tumors and a smaller size. Univariate analysis showed that high VEGF-C was significantly associated with a favourable prognosis for disease-free survival (DFS) and overall survival (OS). No significant prognostic value of VEGFR-3 was detected. Multivariate analysis confirmed the independent prognostic value of VEGF-C. The intratumoral VEGF-C level is a significant prognostic indicator of primary breast cancer. An investigation of the mechanisms of VEGF-C protein processing in human cancer tissue should be carried out in the future.
\end{abstract}

Correspondence to: Dr Masakazu Toi, Metropolitan Komagome Hospital, Tokyo Metropolitan Center for Cancer and Infectious Disease, 3-18-22 Honkomagome Bunkyo-ku, Tokyo 113-8677, Japan E-mail: maktoi77@wa2.so-net.ne.jp

Abbreviations: VEGF, vascular endothelial growth factor; VEGF-C, vascular endothelial growth factor-C; VEGFR-3, vascular endothelial growth factor receptor-3; ELISA, enzyme-linked immunosorbent assay; DFS, disease-free survival; OS, overall survival

Key words: VEGF-C, VEGFR-3, lymphangiogenesis, breast cancer

\section{Introduction}

Lymphangiogenesis is the growth of lymphatic vessels which occurs after tissue injury, obstruction or damage to lymphatic vessels (1). The lymphatic system reduces increased tissue pressure associated with edema and inflammation (2). In the last 5-7 years, it has emerged that the receptor tyrosine kinase VEGFR-3 (Flt-4) and its ligands are key players in the molecular regulation of lymphangiogenesis (3). The two ligands, VEGF-C and VEGF-D, induce the phosphorylation of VEGFR-3 and regulate the growth and differentiation of lymphatic endothelium alone or in combination with other growth factors $(4,5)$. Both ligands are members of the PDGF/ VEGF growth factor super-family and are virtually identical in their molecular properties. They are produced as precursor molecules and are then progressively processed during biosynthesis to remove their $\mathrm{N}$ - and C-terminal ends (6). This processing increases the affinity of VEGF-C and VEGF-D for VEGFR-3, but fully processed forms of both ligands also activate VEGFR-2 (7). Although they are less potent activators of VEGFR-2 than of VEGFR-3, they contribute to normal angiogenesis $(5,7,8)$. However, after binding to VEGF-C and VEGF-D, VEGFR-3 is capable of transducing signals that trigger the proliferation of VEGFR-3 expressing cells in vitro and in vivo (9-11). Blocking VEGFR-3 activation inhibits the formation of lymphatic vessels in the developing embryo (10). VEGFR-3 and its ligands may play an important role in several pathological conditions where lymphangiogenesis occurs or lymphatic is involved. More recent studies suggest that patients with mutations in the VEGFR-3 gene develop lymph-edema $(12,13)$. However, several normal tissues, such as the heart and lung, also express high levels of the VEGF-C gene. This suggests that VEGF-C is necessary for tissue homeostasis, but its exact physiological role is unknown $(14,15)$.

Recently, indirect ELISA was performed to measure VEGF-C protein in cancer patient plasma samples (16). In this assay, it was not possible to use purified VEGF-C standards and, for that reason, only indirect statements can be made about the amount and distribution of VEGF-C in the plasma. 
According to this report, colorectal cancer patients have a 3-fold increased VEGF-C level compared to control patients (16). We developed a sensitive ELISA system for the measurement of the protein levels of processed forms of VEGF-C and VEGFR-3 $(17,18)$. In this study, we quantitatively measured VEGF-C and VEGFR-3 protein levels in breast tumor cytosols and then evaluated their prognostic values. The information from this study is useful for assessing the prognostic value of these markers.

\section{Materials and methods}

Patient population. We randomly selected tissues from 193 patients with operable primary breast cancer who underwent modified radical or partial mastectomy with full dissection of their axillary lymph nodes at the Tokyo Metropolitan Komagome Hospital from 1996-1999. The last follow-up date was 30th November 2004 and the average follow-up period was 71.0 months, with a range of 6.5-99.2 months. Representative samples of the tumor specimens were immediately frozen in liquid nitrogen after surgical resection and stored at $-80^{\circ} \mathrm{C}$ until preparation for ELISA. Pathological examinations were performed on formalin-fixed, paraffin-embedded specimens. The main characteristics of the patients and adjuvant hormone and chemotherapy details are described in Table I. All patients signed an informed consent form according to a protocol approved by the ethics committee of the hospital.

Adjuvant therapy and patient follow-up. Indications for and the schedule of adjuvant treatment were decided based on the patient characteristics including axillary nodal involvement (n), tumor size (T), age and ER. Polychemotherapy including 6 cycles of $\mathrm{CA}(\mathrm{E}) \mathrm{F}$ (cyclophosphamide, adriamycin/epirubicin and 5-FU) was given to node-positive patients under the age of 60 , and FU derivatives were given to the remaining nodepositive and high-risk node-negative patients. Tamoxifen was given to hormone receptor-positive patients without a history of thrombosis or liver dysfunction for 5 years and additional LH-RH agonist therapy was undertaken for 2 years for premenopausal cases. The patients received radiation to the remaining breast if partial mastectomy was performed, and to the chest wall and draining lymph nodes if more than 4 lymph nodes were involved. Post-treatment surveillance was carried out according to general practice for breast cancer patients at our institute. Briefly, for the first 5 years of physical examination, hematology and blood chemistry analyses were performed every 3 months, chest X-rays were taken every 6 months, and mammography was performed annually. Thereafter, physical, blood and chest X-ray examinations were performed every 6 to 12 months, and annual mammography was continued. If tumor relapse was suspected, the patient underwent intensive work-up including chest/abdominal computed tomography scans, isotopic bone scans, bone radiography or histological examination. Survival analysis was performed and the outcomes that were examined included overall survival (OS) and disease-free survival (DFS). OS was calculated from the date of surgery to last contact for living patients. DFS was defined as the period from the date of surgery to the confirmed tumor relapse date for relapsed patients and from the date of surgery to the date of the last follow-up for disease-free patients.
Table I. Patients' characteristics.

\begin{tabular}{|c|c|c|}
\hline \multirow[b]{2}{*}{ Patients enrolled } & \multicolumn{2}{|c|}{ Number of patients (\%) } \\
\hline & 193 & \\
\hline Median age & 54.4 & range $30-86$ \\
\hline \multicolumn{3}{|l|}{ Menopausal status } \\
\hline Pre & 83 & $(43.0)$ \\
\hline Post & 110 & $(57.0)$ \\
\hline \multicolumn{3}{|l|}{ Tumor size (cm) } \\
\hline$<2$ & 25 & $(13.0)$ \\
\hline $2-5$ & 117 & $(60.6)$ \\
\hline$>5$ & 51 & $(26.4)$ \\
\hline \multicolumn{3}{|l|}{ Nodal involvement } \\
\hline+ & 89 & $(46.1)$ \\
\hline- & 104 & $(53.9)$ \\
\hline \multicolumn{3}{|l|}{ ER } \\
\hline Positive & 118 & $(61.1)$ \\
\hline Negative & 75 & $(38.9)$ \\
\hline \multicolumn{3}{|l|}{$\mathrm{PgR}$} \\
\hline Positive & 98 & $(50.7)$ \\
\hline Negative & 95 & $(49.2)$ \\
\hline \multicolumn{3}{|l|}{ Hormonal receptor } \\
\hline $\mathrm{ER}^{+}$and $\mathrm{PR}^{+}$ & 73 & $(37.8)$ \\
\hline $\mathrm{ER}^{+}$and/or $\mathrm{PR}^{+}$ & 56 & $(29.0)$ \\
\hline $\mathrm{ER}^{-}$and $\mathrm{PR}^{-}$ & 64 & $(33.1)$ \\
\hline \multicolumn{3}{|l|}{ Nuclear grade } \\
\hline 1 & 34 & $(17.6)$ \\
\hline 2 & 96 & $(49.7)$ \\
\hline 3 & 63 & $(32.6)$ \\
\hline \multicolumn{3}{|l|}{ Recurrence } \\
\hline+ & 64 & $(33.2)$ \\
\hline- & 129 & $(66.8)$ \\
\hline \multicolumn{3}{|l|}{ Adjuvant therapy } \\
\hline $\mathrm{CAF}(\mathrm{CEF})$ & 51 & $(26.4)$ \\
\hline $\mathrm{CMF}(\mathrm{CF})$ & 17 & $(8.8)$ \\
\hline FU derivatives & 35 & $(18.1)$ \\
\hline Tamoxifen & 111 & $(57.5)$ \\
\hline LH-RH & 10 & $(51.8)$ \\
\hline
\end{tabular}

ER, estrogen receptor; PgR, progesterone receptor; CAF (CEF), cyclophosphamide, adriamycin or epirubicin and 5-FU; $\mathrm{CMF}(\mathrm{CF})$, cyclophosphamide, methotrexate, and 5-FU.

Histopathological analysis. Representative sections from all primary tumors were reviewed and analyzed by pathologists. The special morphological features examined included grade, lymph vessel/blood vessel involvement and the number of lymph nodes involved.

Sample preparation. Breast tumor tissue samples were obtained and the centre of each tumor was individually homogenized in a 10 -fold volume of RIPA buffer $(0.1 \%$ SDS, $1 \%$ Tween-20, 0.5\% Na-deoxycholate, protease-inhibitor cocktail in phosphate-buffered saline, $\mathrm{pH} 7.4$ ) and then centrifuged at $14000 \mathrm{x} \mathrm{g}$ for $20 \mathrm{~min}$. The supernatants were 
Table II. Quantitation of VEGF-C and VEGFR-3 in primary breast cancer tumor cytosol.

\begin{tabular}{|c|c|c|c|c|c|c|c|}
\hline & \multirow[b]{2}{*}{ No. } & \multicolumn{3}{|c|}{ VEGF-C } & \multicolumn{3}{|c|}{ VEGFR-3 } \\
\hline & & Median & Interquartile range & p-value & Median & Interquartile range & $\mathrm{p}$-value \\
\hline Patients enrolled & 193 & 0.326 & $0.163-0.520$ & & 9.13 & $5.578-12.695$ & \\
\hline \multicolumn{8}{|l|}{ Menopause } \\
\hline Pre-menopause & 86 & 0.317 & $0.165-0.516$ & n.s. & 9.679 & 5.928-13.982 & n.s \\
\hline Post-menopause & 116 & 0.342 & $0.160-0.520$ & & 8.062 & $5.350-12.449$ & \\
\hline \multicolumn{8}{|l|}{ Tumor size } \\
\hline $\mathrm{T} 1$ & 25 & 0.408 & 0.191-0.778 & 0.02 & 11.439 & $6.620-14.323$ & 0.03 \\
\hline $\mathrm{T} 2$ & 117 & 0.337 & $0.170-0.533$ & & 9.336 & $6.117-14.204$ & \\
\hline $\mathrm{T} 3$ or more & 51 & 0.244 & $0.129-0.405$ & & 6.495 & $4.200-11.345$ & \\
\hline \multicolumn{8}{|l|}{ Nodal status } \\
\hline $\mathrm{n}-$ & 89 & 0.376 & $0.203-0.548$ & n.s. & 9.269 & $5.433-12.498$ & n.s. \\
\hline $\mathrm{n}+$ & 104 & 0.275 & $0.145-0.475$ & & 9.03 & $5.626-13.240$ & \\
\hline \multicolumn{8}{|l|}{ Hormone receptor } \\
\hline $\mathrm{ER}^{+}$ & 118 & 0.322 & $0.157-0.546$ & n.s. & 8.266 & $5.350-12.369$ & n.s. \\
\hline $\mathrm{ER}^{-}$ & 75 & 0.330 & $0.165-0.514$ & & 9.676 & $5.731-13.663$ & \\
\hline $\mathrm{PgR}^{+}$ & 98 & 0.363 & $0.177-0.638$ & n.s. & 10.099 & $6.032-14.447$ & n.s. \\
\hline $\mathrm{PgR}^{-}$ & 95 & 0.284 & $0.152-0.457$ & & 7.942 & $5.313-12.083$ & \\
\hline \multicolumn{8}{|l|}{ Recurrence } \\
\hline Recurrence + & 64 & 0.247 & $0.121-0.436$ & 0.02 & 7.141 & $4.351-11.704$ & n.s. \\
\hline Recurrence - & 129 & 0.349 & $0.179-0.646$ & & 9.676 & $5.875-14.109$ & \\
\hline \multicolumn{8}{|l|}{ Nuclear grade } \\
\hline 1 & 34 & 0.430 & $0.208-0.744$ & 0.05 & 11.426 & 7.599-18.332 & n.s. \\
\hline 2 & 96 & 0.292 & $0.165-0.455$ & & 7.598 & 5.209-11.506 & \\
\hline 3 & 63 & 0.330 & $0.151-0.479$ & & 10.134 & $5.625-14.406$ & \\
\hline
\end{tabular}

Intratumoral VEGF-C and VEGFR-3 protein levels were measured by quantitative enzyme-linked immunosorbent assays and enzyme immunoassays (see Materials and methods). Results reflect the median, interquartile range and p-value. ER and PgR protein levels more than $5 \mathrm{fmol} / \mathrm{mg}$ total protein were considered positive (+), and less than $5 \mathrm{fmol} / \mathrm{mg}$ total protein was negative (-). The correlation between each biological factor and clinicopathological parameters was analyzed using the Kruskal-Wallis test or Mann-Whitney U test. Differences at $\mathrm{p}<0.05$ were considered to be statistically significant. n.s., not significant.

then stored at $-80^{\circ} \mathrm{C}$ until use. A portion of each supernatant was used for protein concentration measurement according to standard protocols (BCA assay, Pierce, Rockford, IL).

ELISA. We have recently developed a highly sensitive and specific sandwich ELISA for VEGF-C and VEGFR-3 $(17,18)$. Briefly, a polyclonal antibody against rat VEGF-C was developed in rabbits and antigen-affinity purified using $1 \mathrm{mg}$ rVEGF-C on an NHS-activated HiTrap column (Amersham Bioscience, Freiburg). The antibody was used for coating and the same biotinylated antibody was used for detection. As a standard, human and rat dNdC-VEGF-C (a gift from Professor $\mathrm{K}$ Alitalo) were used at concentrations ranging between 0.1 and $6.25 \mathrm{ng} / \mathrm{ml}$. For visualization of the detector, streptavidinenzyme conjugate and TMB were used followed by $0.2 \mathrm{M}$ $\mathrm{H}_{2} \mathrm{SO}_{4}$ as a stopping solution. The samples were at least 1:2 diluted with sample diluent (BenderMedSystems, Vienna). For VEGFR-3 ELISA, a combination of goat polyclonal antiVEGFR-3 antibody (R\&D systems, Abingdon, Oxfordshire, UK) and mouse monoclonal anti-human VEGFR-3 (a gift from Professor K Alitalo) antibody was used for detection. The minimum detection limit was $200 \mathrm{pg} / \mathrm{ml}$.
Estrogen receptor (ER) and progesterone receptor $(\mathrm{PgR})$ levels were determined using enzyme immunoassay systems from the Otsuka Assay Institute (Tokushima, Japan) as previously reported. The cut-off value of EIA for ER and $\mathrm{PgR}$ was $10 \mathrm{fmol} / \mathrm{mg}$ protein.

Generally, the samples were analyzed in different dilutions and each dilution was measured in duplicate.

Statistical methods. The correlation between 2 factors was evaluated using Spearman's correlation coefficient by rank and unpaired groups were compared using the Student's t-test. Univariate and multivariate Cox regression analyses were carried out to assess the potential prognostic indicators of DFS and OS. These features included ER and PgR status, low vs. intermediate and high tumor grades, tumor size ( $5 \mathrm{vs} .>5 \mathrm{~cm}$ ), positive vs. negative axillary lymph node involvement, positive vs. negative lymph vessel involvement, positive vs. negative blood vessel involvement, VEGF-C protein concentration ( $<$ median vs. $>$ median), and VEGFR-3 protein concentration (median vs. $>$ median). All clinical and biological parameters, regardless of whether they were statistically significant by univariate analysis, were included in multivariate analysis. 
Table III. Univariate analysis of clinicopathological and tumor biological factors for disease-free survival and overall survival.

\begin{tabular}{|c|c|c|c|c|c|c|c|}
\hline \multirow[b]{2}{*}{ Parameter } & \multirow{2}{*}{$\begin{array}{c}\text { No. of } \\
\text { total } 193\end{array}$} & \multicolumn{3}{|c|}{ Disease-free survival } & \multicolumn{3}{|c|}{ Overall survival } \\
\hline & & p-value & Hazard ratio & $95 \% \mathrm{CI}$ & p-value & Hazard ratio & $95 \% \mathrm{CI}$ \\
\hline \multicolumn{8}{|l|}{ Clinical features } \\
\hline \multicolumn{8}{|l|}{ ER } \\
\hline Positive & 118 & 0.538 & 0.852 & $0.511-1.420$ & 0.087 & 0.598 & $0.331-1.080$ \\
\hline Negative & 75 & Baseline & & & Baseline & & \\
\hline \multicolumn{8}{|l|}{ Nuclear grade } \\
\hline 1 & 34 & 0.001 & 0.514 & $0.348-0.760$ & 0.001 & 0.447 & $0.278-0.718$ \\
\hline 2 and 3 & 159 & Baseline & & & Baseline & & \\
\hline \multicolumn{8}{|l|}{ Tumor size } \\
\hline $1-5 \mathrm{~cm}$ & 142 & 0.0001 & 0.214 & $0.127-0.361$ & 0.0001 & 0.303 & $0.166-0.555$ \\
\hline $5 \mathrm{~cm}$ or more & 51 & Baseline & & & Baseline & & \\
\hline \multicolumn{8}{|l|}{ Nodal involvement } \\
\hline n positive & 104 & Baseline & & & Baseline & & \\
\hline $\mathrm{n}$ negative & 89 & 0.0001 & 0.198 & $0.102-0.381$ & 0.0001 & 0.22 & $0.102-0.474$ \\
\hline \multicolumn{8}{|c|}{ Lymph vessel involvement } \\
\hline ly positive & 145 & Baseline & & & Baseline & & \\
\hline ly negative & 48 & 0.001 & 0.095 & $0.023-0.390$ & 0.007 & 0.067 & $0.010-0.490$ \\
\hline \multicolumn{8}{|c|}{ Blood vessel involvement } \\
\hline $\mathrm{v}$ positive & 137 & Baseline & & & Baseline & & \\
\hline $\mathrm{v}$ negative & 56 & 0.015 & 0.415 & $0.204-0.846$ & 0.078 & 0.481 & $0.213-1.086$ \\
\hline \multicolumn{8}{|c|}{ Biological features } \\
\hline \multicolumn{8}{|c|}{ VEGF-C (ng/mg protein) } \\
\hline High $(>0.326)$ & 105 & 0.0002 & 0.381 & $0.229-0.634$ & 0.001 & 0.391 & $0.216-0.706$ \\
\hline Low $(<0.326)$ & 88 & Baseline & & & Baseline & & \\
\hline \multicolumn{8}{|c|}{ VEGFR-3 (ng/mg protein) } \\
\hline High $(>9.130)$ & 91 & 0.078 & 0.627 & $0.372-1.055$ & 0.135 & 0.626 & $0.339-1.157$ \\
\hline Low $(<9.130)$ & 102 & Baseline & & & Baseline & & \\
\hline
\end{tabular}

Prognostic parameters evaluated included ER and PR status $(<5 \mathrm{fmol} / \mathrm{mg}$ protein $\mathrm{vs} .>5 \mathrm{fmol} / \mathrm{mg}$ protein), primary tumor size, axillary lymph node involvement, VEGF-C and VEGFR-3 protein levels. For VEGF-C and VEGFR-3 protein level, cut-off values were determined as median values. The median follow-up was 71 months. Survival analysis was performed on 193 cases. The prognostic significance was assessed using the log-rank test. All p-values are two-sided. Hazard ratio indicated Cox model hazard ratio.

Variables that exhibited statistically significant effects were then retained and the others were dropped.

Multivariate analysis resulted in a final model of five prognostic variables for DFS and four prognostic variables for OS. Models were then generated based on the presence or absence of these variables and constructed to assess the relative risk for relapse and death.

Standard Kaplan-Meier and Cox regression methods were applied for survival analysis using StatView statistical software version 5.0 (SAS Institute, Cary, NC). All significance testing was two-sided, where log-rank statistics and Wald statistics were used for univariate and multivariate analysis, respectively. A difference of $\mathrm{p}<0.05$ was considered to be statistically significant.

\section{Results}

The patients' characteristics are listed in Table I. The median age at diagnosis was 54.4 years with a range of 30 to 86 years.
One hundred and three patients $(53 \%)$ underwent adjuvant chemotherapy, and $67 \%$ of the patients with positive receptors underwent adjuvant hormonal therapy. Eighty-one percent of the patients had intermediate- or high-grade tumors.

The protein concentrations of VEGF-C and VEGFR-3 in breast tumor tissue extracts determined by ELISA are listed in Table II. The correlation between each factor and the clinicopathological parameters were analyzed. VEGF-C levels were significantly higher in the smaller tumors and low-grade tumors ( $\mathrm{p}=0.02, \mathrm{p}=0.05$, respectively). VEGF- 3 levels were also higher in the smaller tumors $(\mathrm{p}=0.03)$. There was a significant correlation between the protein levels of VEGF-C and VEGFR-3 $(\mathrm{p}<0.0001, \mathrm{p}=0.697)$, by Spearman's rank correlation test.

To assess the prognostic values of VEGF-C and VEGFR-3, the median values were taken as their cut-off values. For univariate analyses, patients with low-grade tumors $(\mathrm{p}=0.001)$, tumors less than $5 \mathrm{~cm}$ in size $(\mathrm{p}=0.0001)$, no lymph node involvement $(p=0.0001)$, less vessel involvement $(p=0.015$ - 

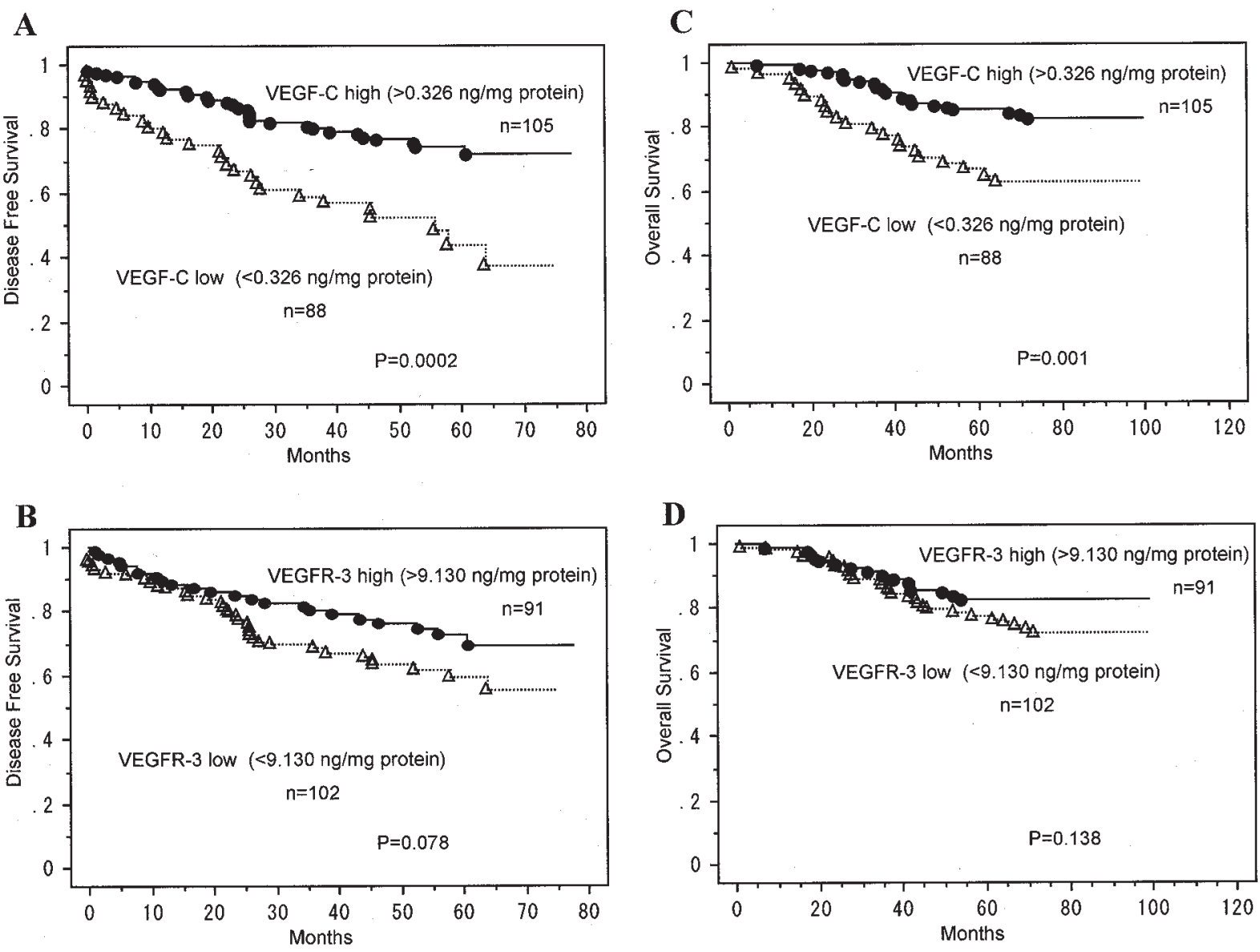

Figure 1. Kaplan-Meier curves for disease-free survival in patients with primary breast cancer by VEGF-C and VEGFR-3 expression levels. Kaplan-Meier curves for disease-free survival in patients with primary breast cancer by VEGF-C and VEGFR-3 expression levels. Disease-free survival in the total cases ( $\mathrm{n}=193$ ) by VEGF-C level (A), VEGFR-3 level (B), and overall survival by VEGF-C level (C), and VEGFR-3 level (D). VEGF-C protein levels more than $0.326 \mathrm{ng} / \mathrm{mg}$ total protein were considered high (solid line with closed circle), and less than $0.326 \mathrm{ng} / \mathrm{mg}$ total protein was negative (dotted line with open triangle) in A and C. VEGFR-3 protein levels more than $9.130 \mathrm{ng} / \mathrm{mg}$ total protein were considered high (solid line with closed circle), and less than $9.130 \mathrm{ng} / \mathrm{mg}$ total protein was negative (dotted line with open triangle) in B and D. A, the hazard ratio $(\mathrm{HR})=0.381[95 \%$ confidence interval $(\mathrm{CI})=0.229$ $0.634, \mathrm{p}=0.0002$ using the log-rank test $]$ in favor of total VEGF-C high group. $\mathrm{B}, \mathrm{HR}=0.627$ (95\% CI $=0.372-1.055$, $\mathrm{p}=0.078 \mathrm{using}$ the log-rank test). Not statistically significant. $\mathrm{C}, \mathrm{HR}=0.391(95 \% \mathrm{CI}=0.216-0.706, \mathrm{p}=0.001$ using the log-rank test $)$ in favor of VEGF-C high group. $\mathrm{D}, \mathrm{HR}=0.626(95 \% \mathrm{CI}=0.339-$ $1.157, \mathrm{p}=0.135$ using the log-rank test). Not statistically significant.

0.001) and a high VEGF-C level ( $\mathrm{p}=0.0002)$ experienced favorable DFS (Table III). Overall survival was also favorable for patients with low-grade tumors $(p=0.001)$, tumors less than $5 \mathrm{~cm}$ in size $(\mathrm{p}=0.0001$, no lymph node involvement $(\mathrm{p}=0.0001)$, less lymph vessel involvement $(\mathrm{p}=0.007)$, and a high VEGF-C level ( $\mathrm{p}=0.001)$. VEGFR-3 did not have a statistically significant effect on patient outcome in the univariate analyses (Table III). Fig. 1 shows DFS and OS curves of the VEGF-C and VEGFR-3 levels.

All tumor- and clinicopathological-related parameters, regardless of whether they were statistically significant by univariate analysis, were included in the multivariate analysis. Variables showing statistically significant effects were retained and the others were dropped. The resulting multivariate analysis revealed that DFS and OS were improved in patients with a high VEGF-C level $(\mathrm{p}=0.015, \mathrm{p}=0.034)$ and low pathological grade $(\mathrm{p}=0.022, \mathrm{p}=0.039$, respectively). Negative nodal involvement $(\mathrm{p}=0.047)$, tumors less than $5 \mathrm{~cm}$ in size $(p=0.005)$, and less lymph vessel involvement was only associated with improved DFS, not with OS (Table IV). VEGFR-3 did not result in improved DFS or OS.

\section{Discussion}

VEGF-C and VEGFR-3 levels are frequently elevated in human breast cancer tissue. We have recently reported the expression of VEGF-A protein levels in primary breast cancer tissue in close-background patients and the protein levels of VEGF-C measured in this study were comparable to the VEGF-A levels (19).

An increasing number of clinicopathological studies have shown a direct correlation between the tumor expression of lymphangiogenesis factors VEGF-C or VEGF-D and metastatic tumor spread in many human cancers, including those of the breast, lung, prostate, cervix, and colon (8), providing circumstantial evidence for the involvement of lymphangiogenesis in tumor progression.

In this study, VEGF-C levels were a potent and independent prognostic indicator in both node-negative and node-positive breast cancer. Unlike previously reported results, high levels of VEGF-C expression were associated with a favorable prognosis. No significant prognostic value for VEGFR-3 was observed. Nodal involvement and vessel invasion status were 
Table IV. Multivariate analysis of clinicopathological and tumor biological factors for disease-free survival and overall survival.

\begin{tabular}{lcccccccc}
\hline & \multicolumn{3}{c}{ Disease-free survival } & & \multicolumn{3}{c}{ Overall survival } \\
\cline { 2 - 3 } Parameter & Hazard ratio & $95 \%$ CI & p-value & & Hazard ratio & $95 \%$ CI & p-value \\
\hline Nuclear grade 1 & 0.190 & $0.046-0.787$ & 0.022 & & 0.123 & $0.017-0.905$ & 0.039 \\
Tumor size $<5 \mathrm{~cm}$ & 0.455 & $0.262-0.792$ & 0.005 & & 0.662 & $0.350-1.254$ & 0.205 \\
Node negative & 0.445 & $0.213-0.930$ & 0.031 & & 0.491 & $0.212-1.136$ & 0.096 \\
Lymph vessel involvement negative & 0.218 & $0.049-0.978$ & 0.047 & & 0.134 & $0.017-1.063$ & 0.057 \\
VEGF-C $>0.325 \mathrm{ng} / \mathrm{mg}$ protein) & 0.487 & $0.271-0.873$ & 0.015 & & 0.490 & $0.254-0.948$ & 0.034 \\
VEGFR-3 $>9.130 \mathrm{ng} / \mathrm{mg}$ protein) & 1.179 & $0.646-2.155$ & 0.591 & & 1.084 & & $0.550-2.138$ & 0.815 \\
\hline
\end{tabular}

Hazard ratio indicates Cox model proportional hazard ratio; $\mathrm{p}$ is the Wald model p-value.

not associated with VEGF-C and VEGFR-3 protein levels. Several hypotheses might be raised to explain why high levels of VEGF-C provide for a significant favorable prognostic value. One of the reasons stems from the difference of the antibody against VEGF-C. VEGF-C is produced as a large precursor molecule and is processed during the release and secretory pathway (6). The largest monomeric unprocessed form is the $58-\mathrm{kDa}$ protein. During the proteolytic processing of VEGF-C by secreted proteases, main bands are seen at 30 and $21 \mathrm{kDa}$ in human PC-3 cells. Mature VEGF-C is a $21-\mathrm{kDa}$ form but it cannot be detected in all VEGF-C-producing cells, and it is not clear if partially unprocessed forms can be secreted to a similar extent or not $(4,6)$ The current study used a highly sensitive VEGF-C ELISA system that can detect the processed form of VEGF-C using an antigen-affinity purified antibody for processed VEGF-C. Other antibodies, such as peptide antibodies, or commercially available sources could not be used or were not sensitive enough to detect the processed form of VEGF-C. In published papers, VEGF-C expression was detected by RT-PCR, in situ hybridization or often by immunohistochemical analysis (20). The major antibodies used in these studies mainly detected unprocessed forms of VEGF-C and cannot detect the processed form. Recently, indirect ELISA was attempted to measure VEGF-C in cancer patient plasma samples (16). According to this report, colorectal cancer patients have a 3-fold increased VEGF-C level if compared to control patients (16). However, this ELISA used two polyclonal antibodies raised in goat and rabbits against the $E$. coli-derived human VEGF-C peptide and against a synthetic peptide corresponding to the $\mathrm{C}$-terminal end of the human VEGF-C precursor. Therefore, they recognize central VEGF-homology and the carboxyl terminal domains of VEGF-C, and it was not possible to measure mature VEGF-C. In our last study using the newly developed VEGF-C ELISA system, we found that conditioned media from PC-3 cells contains relatively low concentrations of VEGF-C and much higher amounts of VEGF-C were detectable in the cell lysate (17). From the beginning of VEGF-C research, PC-3 cells were described as high producers of VEGF-C (4). Thus, we may speculate that only a small amount of VEGF-C protein is processed and secreted from the tumor cells. Further studies are necessary to investigate the biological differences between processed and non- or partially processed forms of VEGF-C.

Another reason is the difference in sample preparation. We aimed to quantify the protein levels of VEGF-C in tumor specimens and used an ELISA system. Representative tumor specimens were excised, lysed and used for measurement. By immunohistochemical analysis, usually the tumor and surrounding tissue are stained, and the strongest intensity is analyzed, which usually exists in the surrounding areas for VEGFR-3, not in the centre of the tumor. VEGF-C is a candidate growth factor for VEGFR-3-positive vessels in carcinomas and, in general, VEGF-C and VEGFR-3 could be components of a paracrine signaling network between cancer cells and the endothelium (15). The expression of large amounts of VEGF-C in tumor surrounding stromal cells and tumor-associated macrophages was also reported (21). The heterogeneity of VEGFR-3 and VEGF-C protein expression within the tumor specimen may lead to the different bioactivity; this needs to be further analyzed.

Other explanations could be considered involving a translational research approach. Recent investigations clarified that peritumor lymphatics often show dysfunction (22). For instance, newly developed lymphatic vessels display a retrograde draining pattern, which might be relevant to possible dysfunction of the intraluminal valves of these vessels. Still, little is known about immature tumor lymphatic formation mechanisms. According to a study on adaptive immunity in the cornea, a blockade of VEGFR-3 signaling significantly suppresses corneal antigen-presenting dendritic cell trafficking to draining lymph nodes, suggesting that the VEGF-C and VEGFR-3 system plays a significant role in peripheral immunity (23). It might be of interest to study the relationship between dysfunctional tumor lymphatics and impaired antitumor immunity.

In conclusion, the intratumoral concentration of VEGF-C was a potent prognostic indicator in 193 primary breast tumors in our study. The results are not totally compatible with those of other previous studies. An investigation of the mechanisms of VEGF-C protein processing in human cancer tissue and its implication in tumor progression should be carried out in the future. 


\section{Acknowledgements}

Professor Kari Alitalo (University of Helsinki, Finland) kindly provided VEGF-C peptide, and the antibodies against VEGF-C and VEGFR-3. This work was partly supported by grants from the Deutsche Forschungsgemeinschaft to HA Weich under the auspices of Schwerpunktprogramm 1069 (Angiogenesis). Dr H. Bando is supported by a fellowship from the International Union Against Cancer (UICC).

\section{References}

1. Pepper M: Lymphangiogenesis and tumor metastasis: myth or reality? Clin Cancer Res 7: 462-468, 2001.

2. Pullinger D and Florey H: Proliferation of lymphatics in inflammation. J Pathol Bacteriol 45: 157, 1937.

3. Korpelainen E and Alitalo K: Signaling angiogenesis and lymphangiogenesis. Curr Opin Cell Biol 10: 159-164, 1998.

4. Joukov V, Pajusola K, Kaipainen A, Chilov D, Lahtinen I, Kukk E, Saksela O, Kalkkinen N and Alitalo K: A novel vascular endothelial growth factor, VEGF-C, is a ligand for the Flt4 (VEGFR-3) and KDR (VEGFR-2) receptor tyrosine kinases. EMBO J 15: 290-298, 1999.

5. Achen M, Jeltsch M, Kukk E, Makinen T, Vitali A, Wilks A, Alitalo K and Stacker S: Vascular endothelial growth factor D (VEGF-D) is a ligand for the tyrosine kinases VEGF receptor 2 (Flk1) and VEGF receptor 3 (Flt4). Proc Natl Acad Sci USA 95: $548-553,1998$

6. Joukov V, Sorsa T, Kumar V, Jeltsch M, Claesson-Welsh L, Cao Y, Saksela O, Kalkkinen N and Alitalo K: Proteolytic processing regulates receptor specificity and activity of VEGF-C. EMBO J 16: 3898-3911, 1997.

7. Joukov V, Kumar V, Sorsa T, Arighi E, Weich H, Saksela O and Alitalo K: A recombinant mutant vascular endothelial growth factor-C that has lost vascular endothelial growth factor receptor-2 binding, activation, and vascular permeability activities. J Biol Chem 273: 6599-6602, 1998.

8. Stacker S, Stenvers K, Caesar C, Vitali A, Domagala T, Nice E, Roufail S, Simpson R, Moritz R, Karpanen T, Alitalo K and Achen M: Biosynthesis of vascular endothelial growth factor-D involves proteolytic processing which generates non-covalent homodimers. J Biol Chem 274: 32127-32136, 1999.

9. Jeltsch M, Kaipainen A, Joukov V, Meng X, Lakso M, Rauvala H, Swartz M, Fukumura D, Jain R and Alitalo K: Hyperplasia of lymphatic vessels in VEGF-C transgenic mice. Science 276: 1423-1425, 1997.

10. Oh S, Jeltsch M, Birkenhager R, McCarthy J, Weich H, Christ B, Alitalo K and Wilting J: VEGF and VEGF-C: specific induction of angiogenesis and lymphangiogenesis in the differentiated avian chorioallantoic membrane. Dev Biol 188: 96-109, 1997.
11. Veikkola T, Jussila L, Makinen T, Karpanen T, Jeltsch M, Petrova T, Kubo H, Thurston G, McDonald D, Achen M, Stacker S and Alitalo K: Signalling via vascular endothelial growth factor receptor-3 is sufficient for lymphangiogenesis in transgenic mice. EMBO J 20: 1223-1231, 2001

12. Irrthum A, Karkkainen M, Devriendt K, Alitalo K and Vikkula M: Congenital hereditary lymphedema caused by a mutation that inactivates VEGFR3 tyrosine kinase. Am J Hum Genet 67: 295-301, 2000.

13. Karkkainen M, Ferrell R, Lawrence E, Kimak M, Levinson K, McTigue M, Alitalo K and Finegold D: Missense mutations interfere with VEGFR-3 signalling in primary lymphoedema. Nat Genet 25: 153-159, 2000.

14. Kirkin V, Mazitschek R, Krishnan J, Steffen A, Waltenberger J, Pepper M, Giannis A and Sleeman J: Characterization of indolinones which preferentially inhibit VEGF-C- and VEGFD-induced activation of VEGFR-3 rather than VEGFR-2. Eur J Biochem 268: 5530-5540, 2001.

15. Kukk E, Lymboussaki A, Taira S, Kaipainen A, Jeltsch M, Joukov V and Alitalo K: VEGF-C receptor binding and pattern of expression with VEGFR-3 suggests a role in lymphatic vascular development. Development 122: 3829-3837, 1996.

16. Duff S, Li C, Renehan A, O'Dwyer S and Kumar S: Immunodetection and molecular forms of plasma vascular endothelial growth factor-C. Int J Oncol 22: 339-343, 2003.

17. Weich H, Bando H, Brokelmann M, Baumann P, Toi M, Barleon B, Alitalo K, Sipos B and Sleeman J: Quantification of vascular endothelial growth factor-C (VEGF-C) by a novel ELISA. J Immunol Methods 28: 145-155, 2004.

18. Bando H, Brokelmann M, Toi M, Alitalo K, Sleeman J, Sipos B, Grone $\mathrm{H}$ and Weich $\mathrm{H}$ : Immunodetection and quantification of vascular endothelial growth factor receptor-3 in human malignant tumor tissues. Int J Cancer 111: 184-191, 2004.

19. Bando H, Weich H, Brokelmann M, Horiguchi S, Funata N, Ogawa T and Toi M: Association between intratumoral-free and total VEGF, soluble VEGFR-1, VEGFR-2 and prognosis in breast cancer. Br J Cancer 92: 553-561, 2005.

20. Stacker S, Baldwin M and Achen M: The role of tumor lymphangiogenesis in metastatic spread. FASEB J 16: 922-934, 2002.

21. Schoppmann S, Birner P, Stockl J, Kalt R, Ullrich R, Caucig C, Kriehuber E, Nagy K, Alitalo K and Kerjaschki D: Tumorassociated macrophages express lymphatic endothelial growth factors and are related to peritumoral lymphangiogenesis. Am J Pathol 161: 947-956, 2004.

22. Isaka N, Padera T, Hagendoorn J, Fukumura D and Jain R: Peritumor lymphatics induced by vascular endothelial growth factor-C exhibit abnormal function. Cancer Res 64: 4400-4404, 2004.

23. Chen L, Hamrah P, Cursiefen C, Zhang Q, Pytowski B, Streilein J and Dana M: Vascular endothelial growth factor receptor-3 mediates induction of corneal alloimmunity. Nat Med 10: 813-815, 2004. 